\title{
Pharmacy Students' Attitudes Towards Learning Communication Skills: The Case Of The United Arab Emirates
}

Tharwat M. El-Sakran, Ph.D., American University of Sharjah, United Arab Emirates Sawsan T. M. El-Sakran, M.Sc., Al Manara Pharmacies, United Arab Emirates

\begin{abstract}
Effective communication amongst pharmacists, especially clinical pharmacists, physicians, nurses, patients, patients' families and relatives and health care personnel is essential. Poor communication does not only lead to frustration and lack of respect among professions but also may compromise patient care if important information is misunderstood, ineffectively conveyed, or left out. This research explores clinical pharmacy students' and clinical pharmacy graduates' attitudes towards the relevance and importance of learning communication skills in their pharmacy careers in the United Arab Emirates. For the purposes of this study, Rees, Sheard, and Davies' (2002) Communication Skills Attitudes Scale (CSAS) is used to measure pharmacy students' and pharmacy graduates' attitudes towards communication skills learning. Although this measure was originally designed to measure medical students' attitudes towards communication skills learning in a European country, the results obtained from our study are not dissimilar to those reported by Rees et al. (2002) in their study. The paper concludes with some practical suggestions for pharmacy experts in charge of pharmacy communication courses.
\end{abstract}

Keywords: Clinical Pharmacy Communication; Medical Communication Skills; Communication Course Design

\section{INTRODUCTION}

1 $\mathrm{t}$ is no longer sufficient to graduate pharmacy students from tertiary institutions with a sound knowledge of pharmacy theory and practice alone. Well-developed professional communication skills, collaborative work practices, effective self-management and a clear understanding of social responsibility and ethical practices are essential for the new pharmacist who hopes to contribute to the profession and build a career. The ability to communicate with patients, nurses, physicians, patients family members, and other health care professionals is one of the most essential skills for pharmacists to properly and appropriately conduct their professional duties. Moreover, effective communication by pharmacists is vital to improve the use of medications by patients and ensure optimal therapeutic outcomes. Changes in the pharmacy profession have strong implications for pharmacists' professional communication skills. The traditional and orthodox concept of a pharmacist as a drugs dispenser has dramatically changed. Nowadays, pharmacists cooperate with physicians, listen to their descriptions of diseases and prescribe the medicine(s) for an illness. Furthermore, in most cases, pharmacists have to speak to patients about medicines, their benefits and side effects, and advise them how to take these medicines. This is a difficult task, specifically when some patients have negative attitudes towards medicines and resist taking them.

These recent changes in the pharmacy field have made it very competitive for clinical pharmacy graduates to get well-paid jobs as clinical pharmacists in plenty of the wide-spread international and multinational medical clinics based in the United Arab Emirates (UAE). To find a suitable pharmacy position in one of these prestigious clinics, graduates of clinical pharmacy departments need, in addition to a clinical pharmacy degree from an accredited university, to be able to execute requisite clinical pharmacy positions duties. 


\section{RESEARCH OBJECTIVE}

Requisite clinical pharmacy graduates' competencies and skills have been of interest to higher education accreditation agencies, academicians, researchers and health care employers. In line with research on teaching and learning effectiveness and in an attempt to reflect-on-action to assess the usefulness of course contents and to better serve learners' needs and workplace requirements, this study explores clinical pharmacy students' reflections on and perceptions of the relevance of communication skills over time: in the early years of their pharmacy study, after doing their pharmacy internship and after graduating and getting a job. In other words, it examines students' perceptions of the relevance of communication skills and whether these perceptions change over time. For the purposes of this study, the concept of relevance is used to measure students' perceptions of the importance of relevance of communication skills they studied in college. This concept is based on Keller's (1983) and Muddiman and Frymier's (2009) definition of relevance as a student's perception of whether course contents satisfy personal needs, personal goals, and/or career goals. Keller's (1983) relevance comprises four constructs: Attention, Relevance, Confidence and Satisfaction (ARCS). Attention refers to the teacher's ability to get students interested in the course. Relevance is the learner's satisfaction with the course, motivation is achieved when the course meets the learner's needs and confidence refers to the student's expectation of getting a higher grade in the course. According to the ARCS model, relevance is achieved when instructors succeed in making students perceive course contents as targeting some requisite or required needs or goals. That is, relevance of the course contents is examined from the users' perspective, "User relevance" (Nolin, 2009). The study aimed to find answers to the following questions:

- What and how many communication courses did the participants study in the university/college of pharmacy?

- $\quad$ Do they consider communication courses essential to their practical life or not?

- $\quad$ Are there any differences between undergraduate pharmacy students and pharmacy graduates in their perceptions and attitudes towards communication courses?

\section{NEED FOR THE STUDY}

The need for this study is threefold: to probe into clinical pharmacy students' perceptions of communication skills and their importance for the work environment, to test the validity of Rees, Sheard and Davies' (2002) communication scale and to report any attitudinal change(s) among students during and after pharmacy education with the view of offering suggestions and recommendations for improving and refining curricula and teaching methods in pharmacy communication courses. Therefore, the results are expected to better inform, benefit and guide clinical pharmacy course designers, especially pharmacy communication courses designers, in the UAE and, perhaps, the whole of the Arab world.

\section{DATA COLLECTION TOOL \& PROCEDURES}

For the purposes of this research, Rees, Sheard and Davies' (2002) communication scale was used (see Appendix B). The survey was used as is, with the exception of a few minor alterations: the word 'doctor' was replaced by 'pharmacist', 'medical degree' by 'pharmacy degree', 'medicine' by 'pharmacy', and the insertion of an extra question (27) as shown in the adapted survey in Appendix B. Overall, the scale comprises 27 items, 13 of which are written in the form of positive statements and 13 needing statements about communication skills learning and a yes-no question asking working pharmacists whether their work experiences have indicated learning other communication skills that they did not study at college. The first 26 items are accompanied by a 5-point Liker scale, ranging from 1 (strongly disagree) to 5 (strongly agree).

\section{Participants}

The participants (279) were female (153) and male (87) undergraduate pharmacy students and graduate pharmacists (39; 13 males and 26 females), whose ages ranged from 18-35, from 5 different pharmacy colleges operating in various locations within the seven emirates of the UAE federation. This helped to give a representative sample of pharmacy colleges' practices nationwide. The undergraduate participants in this study were 102 second year students, 72 third year students and 66 fourth year students. 


\section{PREVIOUS STUDIES}

Pharmacy students' attitudes towards communication skills learning have for long been a concern among pharmacy teachers, curriculum planners and policy makers and have been addressed in a number of studies (McDonough \& Bennett, 2006; Kripalani \& Jacobson, 2007; Hasan, 2008; Kaae, Sørensen, \& Nørgaard, 2011; Mesquita, et al., 2010; Wallman, Vaudan, \& Sporrong, 2013). Rees, Sheard and Davies' (2002) communication skills attitudes scale (CSAS) has been used and validated in the United Kingdom and other parts of the world (e.g., Rees \& Sheard, 2002; Rees \& Sheard, 2003; Cleland, Foster \& Moffat, 2005; Shankar, et al., 2006). McDonough and Bennett (2006) argue that although these studies are cross sectional in nature, they indicate that female students have more positive attitudes than males, and that students have more positive attitudes towards communication courses in their early years of study than in their late years of study. Similar findings are reported in other studies (e.g., Kaufman, et al., 2001; Cleland, Foster \& Moffat, 2005; Shankar, et al., 2006).

\section{RESULTS AND DISCUSSION}

Table 1 displays the overall percentages of relevance obtained from the students' responses:

Table 1. Percentages of communication skills relevance and importance across participants

\begin{tabular}{lcccc}
\hline & Second & Third & Fourth & Graduates \\
\hline 0= No data & $5.4 \%$ & $17.4 \%$ & $25.5 \%$ & $11.4 \%$ \\
1= strongly agree & $48.4 \%$ & $30.1 \%$ & $10.7 \%$ & $28.9 \%$ \\
2=Agree & $31.7 \%$ & $21.8 \%$ & $34.7 \%$ & $45.4 \%$ \\
3= Neutral & $10.4 \%$ & $17.4 \%$ & $11.4 \%$ & $12.4 \%$ \\
4= Disagree & $3.7 \%$ & $9 \%$ & $13 \%$ & $1.9 \%$ \\
5= Strongly Disagree & $0.4 \%$ & $4.3 \%$ & $4.7 \%$ & $0 \%$ \\
\hline
\end{tabular}

In aggregate, $80.1 \%$ of second year students, $51.9 \%$ of third year students, $45.4 \%$ of fourth year students and $74.3 \%$ of graduates find communication skills learning relevant and important. However, it is observed that the total aggregate for second year students shows more positive attitudes towards learning communication skills in comparison with third, fourth year students and graduates. In an attempt to uncover plausible justifications for these differences, it is found out that second year pharmacy students first embarked on their first internship in their second year and, most probably, this made them realize the importance of communication skills in dealing with healthcare professionals during their internship. The same is true of graduate students. Nevertheless, in later years of study, although all respondents still view communication skills learning as important, we notice a change in attitudes towards communication skills which is represented in giving no responses, staying neutral and disagreeing to a big number of the survey questions (see table above). This may be interpreted as delivering a disguised message of disappointment concerning the contents of the so called 'Pharmacy Communication Courses'. That is, while students value communication courses, they are dissatisfied with the contents of these courses. To further verify this point, the researchers checked the curriculum of some pharmacy colleges in the UAE and find out that there was no single course offered under the title 'Communication'. The only courses that claim to touch on communication skills are labeled 'community pharmacy practice'. Upon careful scrutiny of these courses, the researchers noted that they mainly focus on dispensing drugs, reading prescriptions, recording drugs sale, dispensing over the counter medications, placing and organizing drugs on shelves, with no mention of necessary communication skills required for pharmacy practice.

This study, like previous ones mentioned above, noted significant differences in the participants' perceptions regarding the importance of learning communication courses across years of study and after graduation. Nonetheless, significance tests were applied to test if there were differences in the overall perception between male and female participants based on gender, but no significant value was observed. The results also point to the validity of Rees, Sheard, and Davies' (2002) communication scale in measuring pharmacy students' attitudes towards communication skills learning. 


\section{RECOMMENDATIONS AND CONCLUSION}

Based on the above results, we have come to realize that a strong bond should be forged between teaching communication skills and labor market requisite skills. Communication courses should be based on an analysis of students' real needs and should be structured to serve those needs. This highlights the need for designing communication courses that are sensitive to students' professional needs and workplace requirements. In addition, proper testing methods should be developed to verify the materialization of the required communication skills. To conclude, the results of this study are based on students' reported perceptions. Future researchers may decide to follow up students who graduated and ask their employers about their performance and whether they satisfy and meet workplace requirements or not. Others may study the relationship between students' perceptions and their actual performance on field-specific activities or tasks. The results obtained from this study have also made it abundantly clear that we need to get closer to our students and share with them plenty of our questioned educational assumptions. The finding that students' conceptions of teaching and learning are measured by instant benefits calls for instructors' immediate action.

\section{AUTHORS' INFORMATION}

Tharwat M. El-Sakran, Ph.D., is a Professor of Linguistics in the English Department at the American University of Sharjah in the United Arab Emirates. He has published several papers on teaching English for specific purposes, cross-cultural communication, and discourse analysis. He could be reached at the following email: telsakran@aus.edu

Sawsan T. M. El-Sakran, M.Sc., is a licensed Clinical Pharmacist in the UAE. Her research interests are focused on innovation in teaching and learning, using technology in teaching and learning clinical pharmacy and data collection and analysis. She earned her M.Sc. in pharmacotherapy and medicines management from the University of Sunderland in the United Kingdom. She could be contacted at the following email address: sawsantharwat@yahoo.com

\section{REFERENCES}

Cleland, J., Foster, K., \& Moffat, M. (2005). Undergraduate students' attitudes to communication skills learning differ depending on year of study and gender. Med Teach., 27, pp. 246-251. doi: $10.1080 / 01421590400029541$.

Hasan S. (2008). A tool to teaching communication skills to pharmacy students. Am J Pharm Educ. 2008; 15; 72(3), p. 67.

Kaae, S., Sфrensen, E. W., \& Nфrgaard, L. S. (2011). Exploring communications around medication review in community pharmacy. International Journal of Clinical Pharmacy, 33(3), pp. 529-536.

Kaufman, D. M., Laidlaw, T. A., Langille, D., Sargeant, J., \& MacLeod, H. (2001). Differences in medical students' attitudes and self-efficacy regarding patient-doctor communication. Acad Med.,76:188. doi: $10.1097 / 00001888-200102000-00022$

Keller, J. M. (1983). Motivational design of instruction. In Reogleluth, C. M. (Ed.) Instructional design theories: An overview of their current status (pp. 383-434). Hillsdale, NJ: Lawrence Erlbaum.

Kripalani, S., \& Jacobson, K. L. (2007). Strategies to improve communication between pharmacy staff and patients: a training program for pharmacy staff. AHRQ Publication No. 07(08)-0051-1-EF.

McDonough, R. P., \& Bennet, M. S. (2006). Community pharmacy improving communication skills of pharmacy students through effective precepting. Am J of Pharm Educ., 70 (3) Article 58, pp. 1-12.

Mesquita, A. R., Lyra, D. P., Brito, J. R. G., Balisa-Rocha B. J., Aguiar, P. M., \& de Almeida Neto. (2010). Developing communication skills in pharmacy: a systematic review of the use of simulated patient methods. AC Patient Educ Couns. 78(2), pp. 143-148. doi: 10.1016/j.pec.2009.07.012.

Muddiman, A., \& Frymier, A. (2009). What is relevant? Student perceptions of relevance strategies in college classroom. Communication Studies, 6/2, pp. 130-146.

Nolin, J. (2009). Relevance as a boundary concept: Reconsidering early information retrieval. Journal of Documentation, 65/5, pp. 745-767. 
Rees, C., \& Sheard, C. (2002). The relationship between medical students' attitudes towards communication skills learning and their demographic and education-related characteristics. Med Educ., 36, pp.1017-1027. doi: 10.1046/j.1365-2923.2002.01333.x.

Rees, C., \& Sheard, C. (2003). Evaluating first-year medical students' attitudes to learning communication skills before and after a communication skills course. Med Teach., 25, pp. 302-307. doi: $10.1080 / 0142159031000100409$.

Rees, C., Sheard, C., \& Davies, S. (2002). The development of a scale to measure medical students' attitudes towards communication skills learning: The communication skills attitude scale (CSAS). Medical Education, 36, pp. 141-147.

Shankar, R. P., Dubey, A. K., Mishra, P., Deshpande, V. Y., Chandrasekhar, T. S., \& Shivananda P. G. (2006) Student attitudes towards communication skills training in a medical college in Western Nepal. Educ Health (Abingdon), 19, pp. 71-84. doi: 10.1080/13576280500534693.

Wallman, A., Vaudan, C., \& Sporrong, S. K. (2013). Communications training in pharmacy education. Am J Pharm Educ., 77(2), p. 36. 
NOTES 